\title{
Promotional effect of bismuth as dopant in Bi-doped vanadyl pyrophosphate catalysts for selective oxidation of $n$-butane to maleic anhydride
}

\begin{abstract}
Bismuth-promoted (1\% and 3\%) vanadyl pyrophosphate catalysts were prepared by refluxing $\mathrm{Bi}(\mathrm{NO} 3) 3 \cdot 5 \mathrm{H} 2 \mathrm{O}$ and $\mathrm{VOPO} 4 \cdot 2 \mathrm{H} 2 \mathrm{O}$ in isobutanol. The incorporation of $\mathrm{Bi}$ into the catalysts lattice increased the surface area and lowered the overall $\mathrm{V}$ oxidation state. Profiles of temperature programmed reduction (TPR) in $\mathrm{H} 2$ show a significant shift of the maxima of major reduction peaks to lower temperatures for the Bi-promoted catalysts. A new peak was also observed at the low temperature region for the catalyst with $3 \%$ of $\mathrm{Bi}$ dopant. The addition of $\mathrm{Bi}$ also increased the total amount of oxygen removed from the catalysts. The reduction pattern and reactivity information provide fundamental insight into the catalytic properties of the catalysts. Bi-promoted catalysts were found to be highly active $(71 \%$ and $81 \%$ conversion for $1 \%$ and $3 \%$ Bi promoted catalysts, respectively, at $703 \mathrm{~K}$ ), as compared to the unpromoted material (47\% conversion). The higher activity of the Bi-promoted catalysts is due to that these catalysts possess highly active and labile lattice oxygen. The better catalytic performance can also be attributed to the larger surface area.
\end{abstract}

Keyword: bismuth; promoter; vanadyl pyrophosphate; n-butane oxidation 